\title{
INVESTIMENTOS EM ENERGIA ELÉTRICA E DESENVOLVIMENTO: UMA ANÁLISE HISTÓRICA ENTRE 1995 E 2005 NO PARÁ, BRASIL
}

Fabricio Quadros Borges ${ }^{1}$

\section{Resumo}

A energia elétrica detém papel estratégico na medida em que pode contribuir ao melhoramento de vários setores essenciais como saúde, educação, alimentação, água e saneamento. Este artigo possui o objetivo de compreender os reflexos dos investimentos em energia elétrica junto ao processo de desenvolvimento no Pará, por meio dos setores de atividade econômica. A metodologia utilizada neste ensaio fundamentou-se a partir da identificação de correlações lineares entre variáveis vinculadas a energia elétrica e ao processo de desenvolvimento no setor industrial; e a partir da análise crítica da interferência das sinergias setoriais provocadas por estas correlações junto a dinâmica dos investimentos no setor elétrico. O estudo concluiu que os investimentos em energia elétrica, embora em curto prazo possam ocasionar efeitos direcionados na promoção da atividade econômica de determinada região ou país, tendem, em médio e/ou longo prazo, a distorcer as bases sustentáveis de promoção da melhoria do padrão de vida das populações na medida em que o efeito dos investimentos em energia elétrica é uma função das sinergias oriundas do perfil de cada setor econômico, das especificidades regionais verificadas e das políticas setoriais implantadas.

Palavras-chave: Energia elétrica. Investimento em energia. Desenvolvimento socioambiental. Especificidades regionais.

\footnotetext{
${ }^{1}$ Pós-Doutor pelo IPEN/USP. Doutor em Desenvolvimento socioambiental pelo NAEA/UFPA. Mestre em Planejamento do Desenvolvimento pelo NAEA/UFPA. Administrador de Empresas e Economista pela Unama. Professor do Quadro Permanente do Instituto Federal do Pará, em Belém (Brasil). Email: posdoctorborges@gmail.com Orcid: id:https://orcid.org/0000-0002-1326-959XOrcid
}

R. gest. sust. ambient., Florianópolis, v. 10, n. 2, p. 245-266, jun. 2021. 


\title{
INVESTMENTS IN ELECTRICITY AND DEVELOPMENT: A HISTORICAL ANALYSIS BETWEEN 1995 AND 2005 IN PARÁ, BRAZIL
}

\begin{abstract}
Electric energy plays a strategic role in this process as it can contribute to the improvement of several essential sectors such as health, education, food, water and sanitation. This article aims to understand the impact of investments in electric energy in the development process in Pará, through sectors of economic activity. The methodology used in this essay was based on the identification of linear correlations between variables linked to electricity and the development process in the industrial sector; and from the critical analysis of the interference of sectorial synergies caused by these correlations with the dynamics of investments in the electricity sector. The study concluded that investments in electricity, although in the short term, may have a direct effect on the promotion of economic activity in a given region or country, tend, in the medium and / or long term, to distort the sustainable basis for promoting the improvement of the standard of life of the populations insofar as the effect of investments in electric energy is a function of the synergies arising from the profile of each economic sector, the regional specificities verified and the sectoral policies implemented.
\end{abstract}

Keywords: Electricity. Energy investment. Socio-environmental development. Regional specificities.

\section{Introdução}

O setor elétrico é desenvolvido a partir de políticas públicas que pretendem demonstrar que os investimentos objetivam o crescimento econômico e a melhoria da qualidade de vida da população. O desenvolvimento socioeconômico está diretamente vinculado à evolução do setor elétrico, na medida em que a eletricidade é o insumo básico para o melhoramento de outros fatores essenciais como saúde, educação, alimentação, água e saneamento. Todavia, estudos realizados na Amazônia, particularmente no Estado do Pará, desde a década de 80 vêm revelando que as melhorias verificadas na qualidade de vida da população paraense não refletiram proporcionalmente o grande volume de investimentos em energia elétrica, nem os significativos crescimentos da produção e do consumo de eletricidade registrados naquele estado. A política energética sustentada pelo Governo Federal brasileiro não apresentou uma relação direta entre a expansão do setor elétrico e o desenvolvimento socioeconômico da Amazônia, e ainda relegou para segundo plano, questões fundamentais ao amplo desenvolvimento nacional. Neste sentido, esta investigação se propõe responder ao seguinte questionamento: como se desenvolve

R. gest. sust. ambient., Florianópolis, v. 10, n. 2, p. 245-266, jun. 2021. 
a dinâmica dos efeitos dos investimentos em energia elétrica junto ao processo de desenvolvimento? O objetivo desse ensaio portanto, é o de analisar a dinâmica de funcionamento das relações entre os efeitos dos investimentos no setor elétrico paraense e o processo de desenvolvimento por meio dos setores de atividade econômica.

A discussão sobre as relações entre energia elétrica e desenvolvimento socioeconômico vem sendo promovida por inúmeros organismos nacionais e internacionais. Nesta perspectiva, verifica-se que a formulação de políticas públicas para o setor elétrico, como uma das bases impulsoras do desenvolvimento socioeconômico, depende da construção de indicadores baseados na ampla compreensão da dimensão das relações entre os investimentos em eletricidade e o processo de desenvolvimento. Na maior parte dos modelos de construção de índices e indicadores de sustentabilidade energética, vários autores destacam que ainda não foi considerada uma representação da evolução energética que possibilitasse uma avaliação, de modo quantitativo e qualitativo, dos resultados de estratégias e políticas de investimento no setor elétrico para a promoção do desenvolvimento de regiões e países.

\section{Referencial Teórico}

A compreensão do papel do setor elétrico junto ao desenvolvimento socioeconômico está diretamente relacionada ao entendimento de certas categorias de mercado e de estratégias praticadas por meio de políticas públicas articuladas a partir de discursos que pretendem demonstrar que os investimentos objetivam o crescimento econômico e a melhoria das condições de vida da população. Neste sentido, a análise da dinâmica do setor de energia elétrica parte do entendimento das seguintes categorias: produto; demanda e investimento. O universo de entendimento destas categorias representa uma dinâmica combinada. O produto compreende 0 valor total de bens e serviços finais que as unidades produtivas escolhem lançar no mercado para um dado conjunto de circunstâncias (ROSSETTI, 2010). No caso do setor elétrico o produto seria a eletricidade, insumo básico para o melhoramento de vários outros fatores essenciais. A demanda, por seu turno, representa a quantidade de um bem ou serviço que um consumidor deseja e está disposto a adquirir por

R. gest. sust. ambient., Florianópolis, v. 10, n. 2, p. 245-266, jun. 2021. 
determinado preço e em determinado momento. É uma medida da disposição, sujeita ao poder de compra das pessoas, empresas e governo, em seu conjunto, para adquirirem bens ou serviços (PASSOS; NOGAMI, 1998). O setor elétrico constitui-se em uma organização social formada de relações sistêmicas que envolvem 0 processo de transformação da energia primária até a utilização final por tipo de consumidor. Estas relações são estabelecidas entre os componentes do setor elétrico, tais como: geração, transmissão e distribuição. De acordo com Reis, Fadigas e Carvalho (2012), a geração de energia elétrica compreende todo o processo de transformação de uma fonte primária de energia em eletricidade e representa uma parte bastante significativa dos impactos ambientais, socioeconômicos e culturais dos sistemas de energia elétrica. A eletricidade produzida nas centrais de geração percorre normalmente um longo caminho até o seu local de uso. Este percurso envolve os sistemas de transmissão, que interligam a geração aos centros de carga (nos casos onde a distribuição não se conecta diretamente à transmissão utilizam-se os sistemas de subtransmissão). A distribuição, por fim, compreende a rede que interliga a transmissão (ou a subtransmissão) aos pontos de consumo final. O investimento, categoria relevante neste ensaio, significa a aplicação de capital em meios que levam ao crescimento da capacidade produtiva, ou seja, em bens de capital. Trata-se de um componente da demanda e significa uma soma à capacidade produtiva da economia em causa (FILELLINI, 2002). A categoria investimento é ligada à capacidade produtiva, que por sua vez, corresponde ao estoque total de ativos, capazes de produzir um fluxo de insumos economicamente valorizados. De um modo geral, a dinâmica do setor energético atrela-se ao aumento do consumo, da produção e dos investimentos, que por sua vez, não detêm apenas um papel de criar demanda, mas também o de criar nova capacidade produtiva. Assim, quando o investimento é efetuado, a capacidade produtiva se expande. A expansão da capacidade produtiva, por seu turno, permite a expansão do produto. O crescimento do produto induz à expansão da demanda, o que se traduz em melhoria das condições de vida da população, ou seja, em desenvolvimento socioeconômico (FILELLINI, 2002). Deste modo, o setor elétrico nacional possui, a partir de políticas públicas desenvolvidas pelo Ministério de Minas e Energia, o objetivo de direcionar investimentos, com base nos recursos energéticos, econômicos e tecnológicos disponíveis, para a utilização eficiente das

R. gest. sust. ambient., Florianópolis, v. 10, n. 2, p. 245-266, jun. 2021. 
diferentes fontes de energia, procurando atender as demandas do país em todos os seus setores.

O discurso teórico dos autores que estudam o desenvolvimento analisa a evolução das estratégias adotadas para um crescimento econômico equilibrado e auto-sustentado em uma determinada sociedade. Em cômputo geral, o desenvolvimento está vinculado a diversos componentes infra-estruturais dos quais depende para realizar-se como: educação, saúde, transporte, telecomunicações, saneamento e energia (BORGES; BORGES; VATRAZ, 2018). Analisando a história da relação entre o desenvolvimento e, particularmente o componente energia, observa-se que com estratégias voltadas para o uso eficiente deste insumo é possível contribuir ao processo de desenvolvimento socioeconômico, assim como atribuir uma diminuição das pressões sobre o meio ambiente de modo a garantir o abastecimento energético das futuras gerações (REIS; FADIGAS; CARVALHO, 2012). Conforme Goldemberg e Moreira (2005), as relações entre energia e desenvolvimento se revelam desde a utilização das fontes de energia. Para os autores, o uso de fontes de energia e de tecnologias modernas de uso final levou a modificações qualitativas na vida humana, proporcionando tanto o aumento da produtividade econômica quanto do bem-estar da população. Entretanto, como observam os autores, mais do que o aumento do consumo de energia, são os serviços gerados pela energia que realmente conduzem a uma melhoria da qualidade de vida. Serviços energéticos somente são adquiridos por meio de uma combinação de tecnologia, infra-estrutura e suprimento de energia e as formas de alocação são determinantes no nível de desenvolvimento socioeconômico atingido.

A energia, como componente infra estrutural também possui relevância condicional, pois favorece o funcionamento e a dinamização dos setores de atividade econômica. Hirschman (1961) destaca esta importância no atendimento da produção industrial, da sociedade civil e ainda na formação de um ambiente positivo para novos negócios. De acordo com o autor, a infraestrutura é constituída por serviços básicos onde além da energia cita educação, saúde, transporte, poder judiciário, comunicações e saneamento. Neste ambiente, vários autores procuraram compreender as conseqüências que um direcionamento estratégico de investimentos em energia elétrica pode gerar para o conjunto do desenvolvimento socioeconômico regional.

R. gest. sust. ambient., Florianópolis, v. 10, n. 2, p. 245-266, jun. 2021. 


\section{Metodologia}

A metodologia foi operacionalizada em três tarefas: coleta de dados; análise das correlações existentes a partir dos subtemas do desenvolvimento, entre variáveis pertinentes à energia elétrica e variáveis relativas ao desenvolvimento socioeconômico; e a interpretação de resultados. O objeto do presente estudo é o Estado do Pará (IBGE, 2021). Os dados foram coletados e formaram o banco de dados a partir das dimensões: econômica, social, ambiental e política, dentro de cada setor de atividade. Em seguida, desenvolveu-se uma correlação entre variáveis pertinentes à energia elétrica $\mathrm{e}$ variáveis relativas ao desenvolvimento socioeconômico, com base em uma suposição de interdependência entre elas. A correlação buscou como resultado um coeficiente que quantificasse o grau de correlação denominado coeficiente de Pearson $(p)$.

$$
r=\frac{\sum_{i=1}^{n}\left(x_{i}-\bar{x}\right)\left(y_{i}-\bar{y}\right)}{\sqrt{\sum_{i=1}^{n}\left(x_{i}-\bar{x}\right)^{2}} \cdot \sqrt{\sum_{i=1}^{n}\left(y_{i}-\bar{y}\right)^{2}}},
$$

Onde: $x_{1}, x_{2}, \ldots, x_{n}$ e $y_{1}, y_{2}, \ldots, y_{n}$ compreendem os valores medidos de ambas as variáveis. $E$ as equações a seguir são as médias aritméticas destas variáveis:

$$
\bar{x}=\frac{1}{n} \cdot \sum_{i=1}^{n} x_{i} \quad \text { e } \quad \bar{y}=\frac{1}{n} \cdot \sum_{i=1}^{n} y_{i}
$$

As correlações lineares verificadas em cada dimensão, através dos setores, foram descritas e analisadas no tocante a sua importância, representatividade e unidade de medida utilizada. Em momento ulterior as variáveis foram organizadas de acordo com as dimensões: econômicas, sociais, ambientais e políticas. A análise destas correlações tomou por base cada dimensão dos setores de atividade no Estado do Pará, entre 1995 e 2005. Ao analisar as correlações, foi aperfeiçoada a compreensão descritiva dos efeitos empíricos dos efeitos dos investimentos no setor elétrico junto aos meandros do processo de desenvolvimento socioeconômico no Pará. Em seguida, realizou-se uma análise setorial de modo a examinar simultaneamente as dimensões: econômicas, sociais, ambientais e políticas da sustentabilidade energética em cada setor no Pará, de modo a comparar a evolução das variáveis no ambiente setorial à luz das ações públicas e de contingências de

R. gest. sust. ambient., Florianópolis, v. 10, n. 2, p. 245-266, jun. 2021. 
mercado verificadas no período observado. A interpretação de resultados abordou as inferências a partir da compreensão da dinâmica que envolve as relações entre os investimentos em energia elétrica e o processo de desenvolvimento socioeconômico com base no ambiente amazônico. Esta interpretação pretendeu orientar o processo de tomada de decisão no planejamento público de políticas para o setor elétrico.

\section{Resultados e Discussão}

Quanto a análise da sustentabilidade energética do setor industrial no Estado do Pará, apresenta-se a seguir o exame da estratégica da sustentabilidade energética no setor industrial no Estado. A análise está estruturada em duas partes: a primeira desenvolve uma breve caracterização do setor, e a seguinte, apresenta uma análise crítica da sustentabilidade energética do setor baseada em dados empíricos.

O setor industrial é composto por dois grupos: indústria de extração mineral e indústria de transformação (não-metálico, metalúrgico, químico, alimentos, bebida, têxtil, papel e celulose, e outras indústrias). A seguir, desenvolve-se uma análise através das dimensões: econômica, social, ambiental e política no cenário do setor industrial.

A dimensão econômica do setor industrial foi analisada através das seguintes relações: relação entre o valor do PIB industrial e a quantidade de energia elétrica consumida no setor industrial; relação entre o valor do PIB industrial e o número de unidades consumidoras de energia elétrica/empreendimentos no setor industrial; relação entre a tarifa média da eletricidade cobrada por kWh no setor industrial e o PIB industrial; relação entre o valor investido em energia elétrica em todos os setores no Estado e o número de unidades consumidoras de eletricidade/ empreendimentos no setor industrial; e a relação entre o número de unidades consumidoras de energia elétrica/empreendimentos no setor industrial e o valor da tarifa média da eletricidade cobrada por kWh no setor industrial (Tabela 1). Em relação ao valor do PIB industrial e a quantidade de energia elétrica consumida no setor industrial, a correlação linear calculada entre as variáveis apresentou um $(p)=$ 0,0756, ou seja, uma correlação média. Os coeficientes de variação anotaram

R. gest. sust. ambient., Florianópolis, v. 10, n. 2, p. 245-266, jun. 2021. 
36,34\% para o PIB industrial e 14,29\% para o consumo de energia elétrica no mesmo setor.

Tabela 1: PIB, consumo de energia elétrica, $n$ ㅇ. de unidades consumidoras de eletricidade, tarifa média da eletricidade, investimentos efetuados pela Celpa no Pará (1995-2005).

\begin{tabular}{cccccc}
\hline Ano & $\begin{array}{c}\text { PIB no setor } \\
\text { industrial } \\
\text { (em bilhões) }\end{array}$ & $\begin{array}{c}\text { Consumo de } \\
\text { energia } \\
\text { elétrica } \\
\text { no setor industrial } \\
\text { (em GW) }\end{array}$ & $\begin{array}{c}\text { No de unidades } \\
\text { consumidoras de } \\
\text { energia elétrica no } \\
\text { setor industrial }\end{array}$ & $\begin{array}{c}\text { Tarifa média da } \\
\text { eletricidade no } \\
\text { setor industrial } \\
\text { (cobrada por kWh - } \\
\text { R\$) }\end{array}$ & $\begin{array}{c}\text { Investimentos } \\
\text { efetuados pela } \\
\text { Celpa - em } \\
\text { milhōes de US\$ } \\
\text { (**) }\end{array}$ \\
\hline 1995 & 3.619 & 6.663 & 1.819 & 26,12 & 7,20 \\
1996 & 3.950 & 7.176 & 1.996 & 27,75 & 15,50 \\
1997 & 4.280 & 7.115 & 2.044 & 31,92 & 21,80 \\
1998 & 4.371 & 6.910 & 2.330 & 34,91 & 20,90 \\
1999 & 4.712 & 6.889 & 2.526 & 41,58 & 26,20 \\
2000 & 5.516 & 7.000 & 2.766 & 46,05 & 29,50 \\
2001 & 6.859 & 6.307 & 3.180 & 49,35 & 37,10 \\
2002 & 7.868 & 7.581 & 3.617 & 58,36 & 21,50 \\
2003 & 9.634 & 8.504 & 3.818 & 69,01 & 22,40 \\
2004 & 12.310 & 9.909 & 3.878 & 100,13 & 39,30 \\
2005 & $13.680\left(^{*}\right)$ & n.d. $\left.{ }^{* *}\right)$ & 3.902 & 196,68 & 37,30 \\
\hline
\end{tabular}

Fonte: Sepof (2004); Celpa (2006; 2021); ANEEL (2005). (*) Dado baseado na projeção da Sepof (2006). ${ }^{\left({ }^{*}\right)}$ O dado referente ao consumo de energia elétrica em 2005 não está disponível. ( ${ }^{* * *}$ ) O valor de referência do dólar utilizado para o cálculo dos investimentos foi de $R \$ 2,20$

Em relação ao valor do PIB industrial e o número de unidades consumidoras de energia elétrica/empreendimentos no setor industrial, a correlação linear calculada entre as variáveis apresentou um $(p)=0,0018$, isto é, uma baixa correlação. Os coeficientes de variação são 36,34\% para o já mencionado PIB industrial e 37,03\% para o número de unidades consumidoras no setor. O crescimento do produto induz à expansão da demanda, o que se traduz em melhoria das condições de vida da população, como bem destaca Filellini (2002); todavia, o número de unidades consumidoras não possui papel fundamental nesta relação.

No tocante à tarifa média da eletricidade cobrada por kWh no setor industrial e o PIB industrial, a correlação linear calculada entre as variáveis apresentou um $(p)=$ 0,0001, ou seja, a tarifa média da eletricidade cobrada por kWh no setor industrial e o Produto Interno Bruto neste setor apresentaram uma baixa correlação. O coeficiente de variação da tarifa média da eletricidade cobrada por kWh no setor industrial é alto, mais precisamente de $79,99 \%$, bem acima do coeficiente registrado pelo PIB industrial paraense. O PIB compreende o valor total de bens e serviços finais que as unidades produtivas optam em direcionar mercado, diante de um determinado contexto, como bem observa Rossetti (2010), e o PIB precisa ser construído a partir de taxas elevadas no Pará. Neste sentido, os preços das mercadorias produzidas tendem a se elevar.

R. gest. sust. ambient., Florianópolis, v. 10, n. 2, p. 245-266, jun. 2021. 
Quanto ao valor investido em energia elétrica em todos os setores no Estado e o número de unidades consumidoras de eletricidade (empreendimentos) no setor industrial, a correlação linear calculada entre as variáveis apresentou um $(p)=$ 0,0424, ou seja, o valor investido pela distribuidora paraense em eletricidade no Estado e o número de unidades consumidoras de eletricidade/empreendimentos no setor industrial indicam uma correlação média. Os coeficientes de variação, já mencionados, são respectivamente 39,50\% e 37,03\%. Hirschman (1961) alerta sobre a relevância no atendimento da produção industrial. O autor afirma que os investimentos em infraestrutura tendem a contribuir ao conjunto do desenvolvimento socioeconômico regional.

No que concerne ao número de unidades consumidoras de energia elétrica/empreendimentos no setor industrial e o valor da tarifa média da eletricidade cobrada por kWh no setor industrial, a correlação linear calculada entre as variáveis apresentou um $(p)=0,0015$, ou seja, uma baixa correlação.

A dimensão social do setor industrial foi analisada através das seguintes relações: relação entre o valor investido em energia elétrica em todos os setores no Estado e o número de empregos formais gerados no setor industrial; b) relação entre a quantidade de energia elétrica consumida no setor industrial e o coeficiente de Gini registrado no Estado do Pará; e a relação entre o número de unidades consumidoras de energia elétrica/empreendimentos no setor industrial e o coeficiente de Gini registrado no Estado do Pará (Tabela 2). Em relação ao valor investido em energia elétrica em todos os setores no Estado e o número de empregos formais gerados no setor industrial, a correlação linear calculada entre as variáveis apresentou um $(p)=$ 0,0581, ou seja, apontaram correlação média. O coeficiente de variação do investimento no Estado foi de 39,50\%, enquanto o coeficiente de variação do número de empregos gerados no setor industrial registrou um alto índice, mais precisamente de $305,32 \%$. Isto significa que não foi verificada uma relação direta entre os investimentos em energia elétrica no segmento industrial e empregos gerados neste setor.

No tocante à quantidade de energia elétrica consumida no setor industrial e o coeficiente de Gini registrado no Estado do Pará, a correlação linear calculada entre as variáveis apresentou um $(p)=0,0261$, ou seja, uma correlação média. Os coeficientes de variação são respectivamente 14,41\% e 3,63\%. Em relação ao

R. gest. sust. ambient., Florianópolis, v. 10, n. 2, p. 245-266, jun. 2021. 
número de unidades consumidoras de energia elétrica/empreendimentos no setor industrial e o coeficiente de Gini registrado no Estado do Pará, o cálculo da correlação linear entre as variáveis revelou um $(p)=0,0243$, ou seja, uma correlação média.

Tabela 2: Investimento em energia elétrica em todos os setores no Estado e o no. de empregos formais gerados, consumo de energia elétrica, $\mathrm{n}^{\circ}$. de unidades consumidoras de eletricidade no setor industrial no setor industrial e o coeficiente de Gini registrado no Pará (1995-2005)

\begin{tabular}{|c|c|c|c|c|c|}
\hline Ano & $\begin{array}{l}\text { Investimentos } \\
\text { efetuados pela } \\
\text { Celpa } \\
\text { (em milhões de } \\
\text { US\$) (*) }\end{array}$ & $\begin{array}{l}\text { Número de } \\
\text { empregos } \\
\text { formais gerados } \\
\text { no setor } \\
\text { industrial }\end{array}$ & $\begin{array}{l}\text { Consumo de } \\
\text { energia } \\
\text { elétrica no setor } \\
\text { industrial } \\
\text { (em GW) }\end{array}$ & $\begin{array}{l}\text { № de unidades } \\
\text { consumidoras de } \\
\text { eletricidade } \\
\text { (empreendimentos) } \\
\text { no setor industrial }\end{array}$ & $\begin{array}{l}\text { Coeficiente de } \\
\text { Gini registrado no } \\
\text { Estado do Pará }\end{array}$ \\
\hline 1995 & 7,20 & 902 & 6.663 & 1.819 & 0,56 \\
\hline 1996 & 15,50 & 1.256 & 7.176 & 1.996 & 0,58 \\
\hline 1997 & 21,80 & 2.112 & 7.115 & 2.044 & 0,57 \\
\hline 1998 & 20,90 & 1.420 & 6.910 & 2.330 & 0,57 \\
\hline 1999 & 26,20 & 2.644 & 6.889 & 2.526 & 0,56 \\
\hline 2000 & 29,50 & 5.639 & 7.000 & 2.766 & 0,56 \\
\hline 2001 & 37,10 & 2.651 & 6.307 & 3.180 & 0,55 \\
\hline 2002 & 21,50 & 1.907 & 7.581 & 3.617 & 0,56 \\
\hline 2003 & 22,40 & $(1.075)\left({ }^{* *}\right)$ & 8.504 & 3.818 & 0,52 \\
\hline 2004 & 39,30 & 15.546 & 9.909 & 3.878 & 0,52 \\
\hline 2005 & 37,30 & 2.844 & n.d. $\left({ }^{* * *}\right)$ & 3.902 & n.d. $\left({ }^{* * *}\right)$ \\
\hline
\end{tabular}

A dimensão ambiental do setor industrial foi analisada através das seguintes relações: relação entre a quantidade de energia elétrica consumida no setor industrial e o rendimento energético estimado da eletricidade no setor industrial; relação entre o número de unidades consumidoras de energia elétrica/empreendimentos no setor industrial e o rendimento energético estimado da eletricidade no setor industrial; relação entre a quantidade de energia elétrica consumida no setor industrial e a emissão estimada de gás metano $\left(\mathrm{CH}_{4}\right)$ oriundo da geração de energia elétrica no Estado do Pará, por empreendimentos hidroelétricos; e a relação entre o número de unidades consumidoras de energia elétrica/empreendimentos no setor industrial e a emissão estimada de gás metano $\left(\mathrm{CH}_{4}\right)$ oriunda da geração de energia elétrica no Pará, por empreendimentos hidroelétricos (Tabela 3). Em relação à quantidade de energia elétrica consumida no setor industrial e o rendimento energético estimado da eletricidade no setor industrial, a correlação linear calculada entre as variáveis apresentou um $(p)=0,0286$, ou seja, uma correlação média. $O$ coeficiente de variação do rendimento energético não foi calculado em virtude dos dados se tratarem de estimativas.

R. gest. sust. ambient., Florianópolis, v. 10, n. 2, p. 245-266, jun. 2021. 
Em relação à evolução do número de unidades consumidoras de energia elétrica/empreendimentos no setor industrial, produto do atendimento das demandas industriais, e a evolução do rendimento energético da eletricidade dentre as máquinas e equipamentos industriais representaram em conjunto uma relativa expansão qualitativa da utilização da eletricidade no setor. O cálculo da correlação linear entre as variáveis indicou um $(p)=0,0005$, ou seja, o número de unidades consumidoras de eletricidade/empreendimentos no setor industrial e o rendimento energético estimado neste setor apresentaram uma baixa correlação. No tocante à quantidade de energia elétrica consumida no setor industrial e a emissão estimada de gás metano $\left(\mathrm{CH}_{4}\right)$ oriundo da geração de energia elétrica no Estado do Pará, por empreendimentos hidroelétricos, a correlação linear calculada entre as variáveis apresentou um $(p)=0,0436$, ou seja, uma correlação média. O coeficiente de variação das emissões de gás metano $\left(\mathrm{CH}_{4}\right)$ não foi calculado em virtude dos dados se tratarem de estimativas. Em relação ao número de unidades consumidoras de energia elétrica/empreendimentos no setor industrial e a emissão estimada de gás metano $\left(\mathrm{CH}_{4}\right)$ oriunda da geração de energia elétrica no Pará, por empreendimentos hidroelétricos, a correlação linear calculada entre as variáveis apresentou um $(p)=$ 0,0001, ou seja, uma correlação baixa.

Tabela 3: Quantidade de eletricidade consumida no setor industrial, $\mathrm{n}$ - unidades consumidoras de eletricidade / empreendimentos e o rendimento energético estimado da eletricidade no setor industrial e emissão estimada de gás metano $\left(\mathrm{CH}_{4}\right)$ oriunda de hidroelétricas no Pará (1995-2005)

\begin{tabular}{ccccc}
\hline Ano & $\begin{array}{c}\text { Consumo de energia } \\
\text { elétrica no setor } \\
\text { industrial } \\
\text { (em GW) }\end{array}$ & $\begin{array}{c}\text { No de unidades } \\
\text { consumidoras de } \\
\text { eletricidade/ } \\
\text { empreendimentos } \\
\text { no setor industrial }\end{array}$ & $\begin{array}{c}\text { Rendimento energético } \\
\text { estimado da eletricidade } \\
\text { no setor industrial -\% }\left(^{*}\right)\end{array}$ & $\begin{array}{c}\text { Emissão } \\
\text { estimada de gás } \\
\text { metano }\left(\mathrm{CH}_{4}\right) \text { em } \\
\text { toneladas }\left(^{* *}\right)\end{array}$ \\
\hline 1995 & 6.663 & 1.819 & 67,0 & 71,0 \\
1996 & 7.176 & 1.996 & 67.6 & 142,0 \\
1997 & 7.115 & 2.044 & 68,2 & 213,0 \\
1998 & 6.910 & 2.330 & 68,8 & 354,0 \\
1999 & 6.889 & 2.526 & 69,4 & 426,0 \\
2000 & 7.000 & 2.766 & 70,0 & 497,0 \\
2001 & 6.307 & 3.180 & 70,6 & 568,0 \\
2002 & 7.581 & 3.617 & 71,2 & 639,0 \\
2003 & 8.504 & 3.818 & 71,8 & 710,0 \\
2004 & 9.909 & 3.878 & 73,4 & 781,0 \\
2005 & n.d. $\left({ }^{* * \star}\right)$ & 3.902 & 73,0 & 0 \\
\hline
\end{tabular}

Fonte: Celpa (2006; 2021); BEU (2000). O dado referente ao consumo de energia elétrica em 2005 não se encontra disponível. ${ }^{*}$ ) Os anos em que o rendimento energético da eletricidade não foi calculado pelo Balanço de Energia Útil (BEU), foram atribuídas estimativas pautadas em variações anuais anteriores divulgadas pelo BEU. $\left({ }^{* *}\right) O$ cálculo das estimativas de emissão de metano $\mathrm{CH}_{4}$ baseou-se em Santos (2000). O ano de referência utilizado para o cálculo da quantidade estimada de metano foi 1995 , ou seja, início do período analisado neste estudo. $\quad\left({ }^{* * *}\right)$ O dado referente ao ano de 2005 não está disponível

R. gest. sust. ambient., Florianópolis, v. 10, n. 2, p. 245-266, jun. 2021. 
A dimensão política do setor industrial foi analisada através das seguintes relações: relação entre a tarifa média da energia elétrica cobrada por kWh no setor industrial e a Frequência equivalente de interrupção por unidade consumidora/empreendimento (FEC) do Estado do Estado; e a relação entre o número de unidades consumidoras de energia elétrica/empreendimentos no setor industrial e a frequência equivalente de interrupção por unidade consumidora/empreendimento no Estado do Pará (Tabela 4). Em relação à tarifa média da energia elétrica cobrada por kWh no setor industrial e a Frequência equivalente de interrupção por unidade consumidora/empreendimento (FEC) do Estado do Estado, a correlação linear calculada entre as variáveis apresentou um ( $p$ ) $=0,0444$, ou seja, uma correlação média. Quanto ao número de unidades consumidoras de energia elétrica/empreendimentos no setor industrial e a frequência equivalente de interrupção por unidade consumidora/empreendimento no Estado do Pará, a correlação linear calculada entre as variáveis apresentou um $(p)=0,0887$, ou seja, uma correlação média. Os coeficientes de variação são próximos e anotaram respectivamente $35,86 \%$ e $30,35 \%$.

Em resumo, por meio desta análise, verificou-se que o papel do setor elétrico, através dos investimentos em energia elétrica e do consumo deste insumo, na dinâmica do desenvolvimento socioeconômico do setor industrial no Estado do Pará está na possibilidade de ampliação do PIB no setor, na viabilização do progresso técnico que alicerça o desenvolvimento de novos ramos e processos industriais e na alteração do padrão tecnológico para a consolidação do crescimento industrial e, por conseguinte do padrão de acumulação. A importância da indústria é fundamental em qualquer economia; contudo, para que o Pará caminhe em direção a uma estratégia energética sustentável, faz-se necessário um redirecionamento do seu perfil industrial.

R. gest. sust. ambient., Florianópolis, v. 10, n. 2, p. 245-266, jun. 2021. 
Tabela 4: Tarifa média da eletricidade cobrada por kWh, número de unidades consumidoras de eletricidade/empreendimentos no setor industrial e a FEC do Estado do Pará (1995-2005)

\begin{tabular}{cccc}
\hline Ano & $\begin{array}{c}\text { Tarifa média da } \\
\text { eletricidade cobrada por } \\
\text { kWh (R\$) }\end{array}$ & $\begin{array}{c}\text { No. de unidades } \\
\text { consumidoras de } \\
\text { eletricidade } \\
\text { (empreendimentos) }\end{array}$ & $\begin{array}{c}\text { Frequência equivalente } \\
\text { de interrupção por } \\
\text { empreendimento (\%) }\end{array}$ \\
\hline 1995 & 26,12 & 1.819 & 47,30 \\
1996 & 27,75 & 1.996 & 52,38 \\
1997 & 31,92 & 2.044 & 59,04 \\
1998 & 34,91 & 2.330 & 64,66 \\
1999 & 41,58 & 2.526 & 35,17 \\
2000 & 46,05 & 2.766 & 30,26 \\
2001 & 49,35 & 3.180 & 31,72 \\
2002 & 58,36 & 3.617 & 38,37 \\
2003 & 69,01 & 3.818 & 31,81 \\
2004 & 100,13 & 3.878 & 30,77 \\
2005 & 196,68 & 3.902 & 31,35 \\
\hline Fonte: Celpa (2006; 2021); ANEEL (2002; 2005) & & \\
\multicolumn{4}{r}{}
\end{tabular}

Observa-se que quando as pesquisas realizadas desde a década de 1980 revelavam que as melhorias verificadas na qualidade de vida da população do Pará refletiram apenas discretamente o grande volume de investimentos no setor energético e os significativos crescimentos da produção e do consumo de eletricidade registrados naquele estado, demonstram que o perfil setorial e as especificidades identificadas no ambiente de cada setor de atividade promovem sinergias que interferem nos efeitos destes investimentos em direção ao processo de desenvolvimento socioeconômico. A relevância do perfil dos setores econômicos e das especificidades regionais junto aos efeitos dos investimentos em energia elétrica revela suas dimensões dentro do próprio ambiente amazônico. Observe uma comparação de dados entre o Estado do Pará e o Estado do Amazonas, entre os anos de 2000 e 2005. Ambos apresentam algumas semelhanças: estão localizados na região amazônica; possuem ampla extensão territorial, com áreas geográficas, respectivamente, de $1.247 .689,515 \mathrm{~km}^{2}$ e $1.570 .745,680 \mathrm{~km}^{2}$; e possuem populações de perfil urbano, com registros de $67 \%$ e $74 \%$, respectivamente, de seus habitantes residindo em grandes cidades. Entretanto, o perfil dos setores econômicos e as especificidades locais em cada estado apresentam naturalmente particularidades. Enquanto a base econômica paraense está pautada em dois pilares: na agroindústria e na produção mineral; a economia amazonense baseia-se na indústria, no extrativismo, inclusive de petróleo e gás natural, mineração e pesca. No Pará a pecuária é a principal ocupação de $51 \%$ dos municípios, já no Amazonas observa-se um histórico extrativista desde a exploração do látex, durante o ciclo da borracha.

R. gest. sust. ambient., Florianópolis, v. 10, n. 2, p. 245-266, jun. 2021. 
Politicamente, o Estado paraense está dividido em 143 municípios, enquanto o Estado amazonense detém apenas 62.

Verifica-se nesta perspectiva, que as dimensões econômicas, sociais, políticas e ambientais se estruturam a partir das mais diversificadas sinergias dentro de cada setor de atividade econômica, e consequentemente, estes estados apresentam ambientes complexos e diferenciados entre si, e que absorvem diferentemente os investimentos em energia elétrica. Apesar destes investimentos não serem os únicos responsáveis pelo processo de desenvolvimento socioeconômico de regiões e países, ao lado do setor de transportes, o setor elétrico compreende o setor de maior contribuição à dinamização das atividades produtivas, além de deter papel estratégico na medida em que a energia elétrica é o insumo básico para o melhoramento de vários setores essenciais. As informações a seguir, possibilitam uma avaliação através de algumas categorias capazes de demonstrar os diferentes cenários socioeconômicos, entre os estados, a partir dos efeitos oriundos dos investimentos em eletricidade. As categorias são: população, PIB, saldo de empregos formais, índice de Gini, renda per capta e consumo de energia elétrica (Tabela 5).

Tabela 5: População, PIB, saldo de empregos formais, índice de Gini, renda per capita em R\$ e consumo de eletricidade em GWh nos Estados do Pará e do Amazonas (2000-2005).

\begin{tabular}{l|c|c|c|c|c|c}
\hline \multirow{2}{*}{\multicolumn{1}{c}{ CATEGORIAS }} & \multicolumn{3}{c}{ ESTADO DO PARÁ } & \multicolumn{3}{c}{ ESTADO DO AMAZONAS } \\
\cline { 2 - 7 } & $\mathbf{2 0 0 0}$ & $\mathbf{2 0 0 5}$ & $\begin{array}{c}\text { Variação } \\
(\%)\end{array}$ & $\mathbf{2 0 0 0}$ & $\mathbf{2 0 0 5}$ & $\begin{array}{c}\text { Variação } \\
(\%)\end{array}$ \\
\hline População & 6.272 .661 & 6.734 .106 & 7,3 & 2.812 .557 & 3.232 .330 & 14,9 \\
PIB em bilhões de $\mathrm{R} \$$ & 17.929 & 38.000 & 111,9 & 17.080 & 39.800 & 133,0 \\
Saldo de empregos & 15.279 & 17.780 & 16,4 & 13.044 & 19.939 & 52,8 \\
Índice de Gini & 0,56 & $0,52\left(^{*}\right)$ & $(7,1)$ & 0,68 & $0,62\left(^{\star}\right)$ & $(8,8)$ \\
Renda per capita & 3.393 & 4.367 & 28,7 & 7.086 & 9.100 & 28,4 \\
Consumo de energia & 10.132 & 13.330 & 31,6 & 2.882 & 4.098 & 42,2 \\
\hline
\end{tabular}

Fonte: Elaboração própria (2021) com base em dados da Celpa (2004); Ceama (2005; 2004); IBGE (2004); Caged (2021). (*) Valor referente a 2004.

Os dados demonstram que o desempenho do PIB e do saldo de empregos formais no Estado do Amazonas é superior ao do Estado paraense. A renda per capita de ambos os Estados apresenta similaridade, entretanto, a população amazonense cresce de forma bem mais acelerada que a paraense. Destaca-se ainda, que apesar das semelhantes proporções no PIB, a população do Estado do Amazonas é menos que a metade da população do Pará. No tocante ao índice de Gini, onde quanto mais próximo a 1, maior a concentração de renda, o Estado do

R. gest. sust. ambient., Florianópolis, v. 10, n. 2, p. 245-266, jun. 2021. 
Amazonas apresentou um progresso acima do Estado paraense. Neste sentido, verificou-se um melhor aproveitamento da energia elétrica no panorama amazonense.

O perfil setorial e suas sinergias não são elementos idênticos nos países ou regiões, por isso os efeitos dos investimentos em energia elétrica só podem ser previstos operacionalmente a partir da identificação das dinâmicas setoriais, através de correlações lineares, e da compreensão de seus comportamentos diante da ação destes investimentos. Assim, a utilidade operacional desta constatação surge no momento em que se verifica que a dinâmica das sinergias apresentadas pelo perfil dos setores de uma economia e das especificidades regionais, quando acionadas pelos investimentos em energia elétrica, deve ser pilar de orientação estratégica ao planejamento no setor elétrico. As sinergias setoriais compreendem mecanismos de dinamização da atividade produtiva que agem de acordo com o nível de desenvolvimento das cadeias produtivas no interior destes setores e a partir do grau de integração entre as conexões destas cadeias. Nesta perspectiva, a homogeneidade e a conseqüente eficácia dos efeitos dos investimentos em energia elétrica dependem da habilidade dos governos em fazer uso estratégico e integrado de seu poder de gerenciar suas políticas: agrícola, industrial e de comércio.

Assim, a expressão matemática que poderia melhor caracterizar esta dinâmica seria:

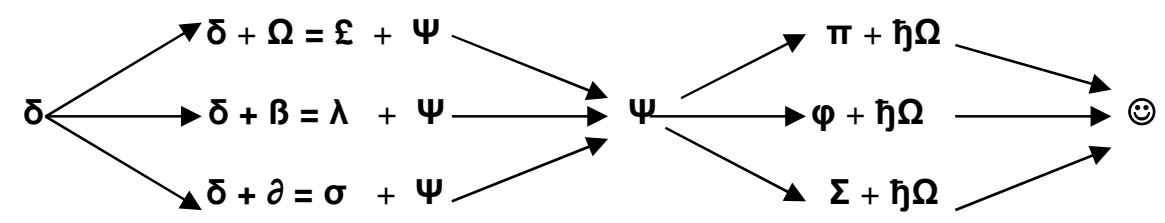

Onde:

$\delta=$ investimentos em energia elétrica

$\mathbf{\Omega}=$ setor agropecuário

$B=$ setor industrial

$\partial=$ setor comercial

$\mathcal{E}=$ efeitos dos investimentos em energia elétrica no setor agropecuário

$\boldsymbol{\lambda}=$ efeitos dos investimentos em energia elétrica no setor industrial

$\boldsymbol{\sigma}=$ efeitos dos investimentos em energia elétrica no setor comercial

$\boldsymbol{\Psi}=$ especificidades regionais

$\pi=$ efeitos dos investimentos em energia elétrica no setor agropecuário considerando as especificidades locais da região

$\boldsymbol{\varphi}=$ efeitos dos investimentos em energia elétrica no setor industrial considerando as especificidades locais da região

$\boldsymbol{\Sigma}=$ efeitos dos investimentos em energia elétrica no setor comercial considerando as especificidades locais da região

$\hbar \Omega=$ ações estratégicas e integradas por parte dos governos

() = efeito onde os investimentos em energia elétrica são capazes de promover homogeneamente o desenvolvimento socioeconômico

R. gest. sust. ambient., Florianópolis, v. 10, n. 2, p. 245-266, jun. 2021. 
Verifica-se que quando o investimento em energia elétrica (ס) é aplicado nos setores econômicos (agropecuário - $\mathbf{\Omega}$, industrial - $\mathbf{B}$ ou comercial - $\partial$ ), ele ocasiona resultados diferenciados nestes setores ( $£$ para o setor agropecuário, $\boldsymbol{\lambda}$ para o setor industrial e $\boldsymbol{\sigma}$ para o setor comercial), isto é, as características estruturais de cada setor, como perfil de consumo de eletricidade ou capacidade de geração de empregos, ou ainda os impactos ambientais deste setor, ao utilizar o insumo energético, interferem nos efeitos dos investimentos junto ao processo de desenvolvimento. Estes diferentes resultados setoriais ainda são agregados às especificidades regionais $(\boldsymbol{\Psi})$, como potencial tecnológico, ou propensão a determinadas atividades econômicas, que pode se utilizar em proporções e intensidades diferentes do insumo energético e, portanto, produzindo resultados diferentes ( $\boldsymbol{\pi}$ para o setor agropecuário, $\boldsymbol{\varphi}$ para o setor industrial e $\boldsymbol{\Sigma}$ para o setor comercial). Assim, caracteriza-se a dinâmica verificada na realidade dos resultados satisfatórios registrados no Estado do Pará. É neste momento que se apresenta uma nova variável a esta expressão matemática, as ações estratégicas e integradas por parte dos governos $(\boldsymbol{\zeta} \Omega)$. É justamente a interferência destas ações junto aos resultados finais de cada setor de atividade que será capaz de promover uma relativa homogeneidade dos efeitos dos investimentos em energia elétrica, de modo a produzir um resultado estratégico e progressivo (@) no tocante ao papel de fator dinâmico do insumo energético junto ao desenvolvimento socioeconômico. Neste sentido, o efeito dos investimentos em energia elétrica junto à dinâmica do desenvolvimento de regiões e países compreende uma função do perfil dos setores econômicos, das especificidades regionais e de políticas setoriais estrategicamente planejadas. $O$ que se demonstra através da expressão:

$$
\text { (:) }=f(\mu, \Psi, ђ \Omega)
$$

Onde:

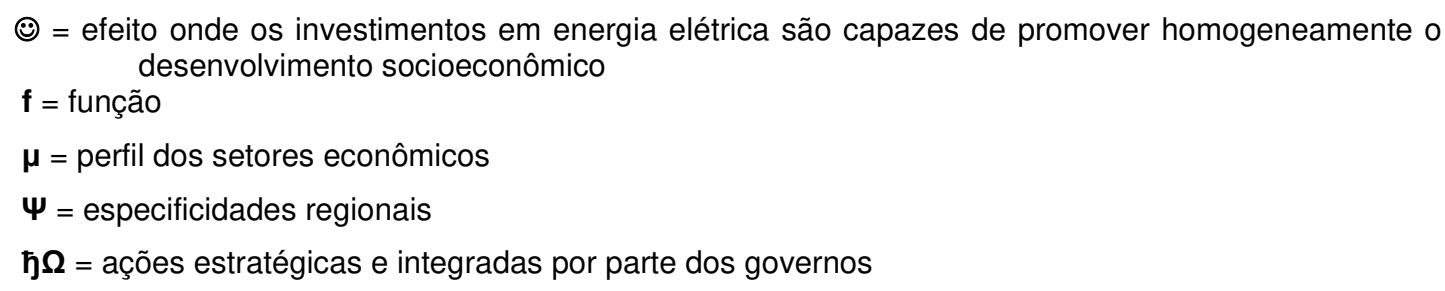

R. gest. sust. ambient., Florianópolis, v. 10, n. 2, p. 245-266, jun. 2021. 
O investimento, como bem observa Keynes (1989), é o fator dinâmico geral da economia na medida em que promove o pleno emprego e influencia a demanda. Todavia, em ambientes específicos, como aquele que envolve as relações entre o setor elétrico e o processo de desenvolvimento, destaca-se a necessidade de compreensão da dinâmica da relação entre variáveis endógenas de cada setor econômico na medida em que interferem para que os investimentos possam, de fato, promover o pleno emprego e influenciar a demanda em economia de regiões e países. A dinâmica dos investimentos em energia elétrica revela que, embora em curto prazo possam ocasionar efeitos direcionados na promoção da atividade econômica de determinada região ou país, tende, em médio e/ou longo prazo, a distorcer as bases sustentáveis de promoção da melhoria do padrão de qualidade de vida das populações através da dinâmica heterogênea que estes investimentos exercem junto à natureza dos setores de atividade que podem, inclusive, ser potencializados em maior ou em menor proporção a partir do perfil das especificidades locacionais existentes em cada região. Esta constatação foi demonstrada a partir do ambiente amazônico, particularmente no Estado do Pará. O setor industrial indicou que a contribuição destes investimentos esteve possibilidade de ampliação do PIB no setor; viabilização do progresso técnico que alicerça o desenvolvimento de novos ramos e processos industriais; alteração do padrão tecnológico para a consolidação do crescimento industrial; e modificação do padrão de acumulação. É relevante destacar que a grande utilidade deste ensaio, não consiste na identificação de especificidades regionais ou na percepção de que cada setor econômico reage diferentemente a partir de investimentos em energia elétrica, mas na identificação de como estas especificidades e reações setoriais se desenvolvem, quando da utilização do insumo energético, em direção ao processo de desenvolvimento.

Os perfis de funcionamento dos setores de atividade econômica não são idênticos entre si, nem absolutamente idênticas, são as especificidades entre regiões e/ou países. Todavia, esta constatação não possui utilidade caso não sejam conhecidas, primeiramente, as nuances, sinergias e suas intensidades junto à dinâmica em cada setor econômico, quando acionada pelos investimentos em energia elétrica; e posteriormente, sejam identificados os resultados dos efeitos dos

R. gest. sust. ambient., Florianópolis, v. 10, n. 2, p. 245-266, jun. 2021. 
investimentos em energia elétrica na estrutura setorial e nas dimensões do processo de desenvolvimento socioeconômico.

As características dos setores de atividade econômica atuam no momento em que as características estruturais de cada setor, como o comportamento do consumo de eletricidade ou a capacidade de geração de empregos, ou ainda os impactos ambientais promovidos por este setor, ao utilizar o insumo energético, representam elemento de intervenção nos efeitos dos investimentos junto ao processo de desenvolvimento. O Estado do Pará demonstra claramente esta dinâmica quando se observa que enquanto o consumo no setor agropecuário, em 2004, foi de 0,011 GWh por empreendimento e no setor comercial, de 0,008 GWh por empreendimento, o consumo de energia elétrica no setor industrial foi de 2.778 GWh por empreendimento. Quanto às especificidades regionais, o Pará revela espessos efeitos da articulação entre agregados urbanos de baixa densidade promotores de uma dinâmica de fronteira, onde as decisões; quanto ao que e como produzir; estão fortemente influenciadas tanto pelas grandes reservas de terras, quanto pela possibilidade prática da continuidade da apropriação de terras novas na dimensão do poder econômico e político do interessado. Este ambiente interfere nos efeitos dos investimentos em eletricidade na medida em que o fator terra revela preponderância neste cenário. As especificidades regionais no estado também revelam uma base produtiva pautada em dois pilares: a agroindústria e a produção mineral.

Por fim, destaca-se que as ações articuladas pelo Governo do estado no setor elétrico paraense apresentaram progressos relevantes na ampliação da taxa de eletrificação e no suporte infra estrutural para a promoção de novos negócios, mas suas políticas não revelam perceber que o papel estratégico que a energia elétrica pode exercer na melhoria da qualidade de vida de sua população está na eficiência dos efeitos dos investimentos neste insumo, e o aperfeiçoamento destes efeitos junto ao processo de desenvolvimento socioeconômico está condicionado à implantação de ações públicas que reconheçam que o resultado dos efeitos dos investimentos em eletricidade é uma função do perfil dos setores econômicos, das especificidades regionais e de políticas setoriais planejadas.

R. gest. sust. ambient., Florianópolis, v. 10, n. 2, p. 245-266, jun. 2021. 


\section{Conclusão}

Esta investigação desenvolveu uma tentativa em responder como se desenvolve a dinâmica dos efeitos dos investimentos em energia elétrica na estrutura de uma economia a através das dimensões do processo de desenvolvimento de regiões e países, tomando como objeto de estudo para demonstração o ambiente amazônico. A investigação partiu do princípio de que se o papel do setor elétrico no desenvolvimento socioeconômico de uma região ou país se concretiza na medida em que promove alterações fundamentais no padrão de vida da população, estas alterações só se desenvolverão plenamente no momento em que se compreende a dinâmica de funcionamento entre os efeitos dos investimentos em eletricidade e o processo de desenvolvimento socioeconômico de uma região ou país. A intenção desta compreensão é a de fornecer subsídios à orientação estratégica da tomada de decisão no setor elétrico. Nesta perspectiva o ensaio verificou que os investimentos em energia elétrica, embora em curto prazo possam ocasionar efeitos direcionados na promoção da atividade econômica de determinada região ou país, tendem, em médio e/ou longo prazo, a distorcer as bases sustentáveis de promoção de melhoria do padrão de qualidade de vida das populações através da dinâmica heterogênea que estes investimentos exercem junto à natureza econômica, social, política e ambiental dos setores de atividade que podem, inclusive, ser atingida, em maior ou em menor proporção, a partir do perfil das especificidades regionais existentes.

Assim, utilizou-se o ambiente amazônico, particularmente o Estado do Pará, na tentativa de alcançar estes propósitos. A realidade no setor industrial demonstrou que a contribuição do setor de energia elétrica está na: possibilidade de ampliação do PIB no setor; viabilização do progresso técnico que alicerça o desenvolvimento de novos ramos e processos industriais; alteração do padrão tecnológico para a consolidação do crescimento industrial; e modificação do padrão de acumulação. Observadas as nuances, sinergias suas intensidades, apresentam-se agora as inferências a respeito da identificação da dinâmica dos efeitos dos investimentos em energia elétrica na estrutura da economia paraense e nas dimensões do seu processo de desenvolvimento socioeconômico. O ensaio observa que os efeitos dos investimentos representam um ambiente que interage com o perfil dos setores econômicos, com as especificidades regionais e políticas setoriais.

R. gest. sust. ambient., Florianópolis, v. 10, n. 2, p. 245-266, jun. 2021. 
Quanto às políticas setoriais, verificou-se que quando as ações públicas são planejadas estrategicamente, são capazes de promover a homogeneidade e conseqüente maior eficácia dos efeitos dos investimentos em energia elétrica em favor do desenvolvimento, na medida em que reúnem condições de alicerçar a criação de mecanismos de gestão dentro de cada setor de atividade econômica, capazes de melhor absolver o investimento no insumo energético, enquanto fator dinâmico das economias, e, simultaneamente, possibilitar que estes setores se fortaleçam estrategicamente no enfrentamento da heterogeneidade verificada junto aos resultados dos efeitos destes investimentos.

Em cômputo geral, concluiu-se que o efeito dos investimentos em energia elétrica junto à dinâmica do desenvolvimento socioeconômico compreende uma função do perfil dos setores econômicos, das especificidades regionais e de políticas setoriais estrategicamente planejadas. Assim, a preocupação central dos governos diante desta constatação deve ser a de desenvolver um planejamento público estratégico e integrado de ações, onde a homogeneidade e a conseqüente maior eficácia do efeito dos investimentos em energia elétrica seriam alicerçadas pela criação de mecanismos específicos dentro de cada setor de atividade econômica.

Nesta perspectiva, o aperfeiçoamento dos efeitos dos investimentos do setor elétrico em direção ao desenvolvimento de regiões e países depende da habilidade dos governos em fazer uso estratégico de seu poder de gerenciar integradamente suas políticas: agrícola, industrial e de comércio. A partir desta constatação, a preocupação central dos governos deve ser a de desenvolver um planejamento público estratégico e integrado de ações onde a homogeneidade e consequente aperfeiçoamento dos efeitos dos investimentos em energia elétrica sejam alicerçados pela criação de mecanismos dentro de cada setor de atividade econômica, capazes de melhor absolver estes investimentos, enquanto fator dinâmico de economias, e, simultaneamente, possibilitar que estes setores se fortaleçam estrategicamente no enfrentamento da heterogeneidade verificada junto aos resultados dos efeitos destes investimentos.

R. gest. sust. ambient., Florianópolis, v. 10, n. 2, p. 245-266, jun. 2021. 


\section{REFERÊNCIAS}

AGÊNCIA NACIONAL DE ENERGIA ELÉTRICA (ANEEL). Atlas de energia elétrica do Brasil. Brasília, 2002.

AGÊNCIA NACIONAL DE ENERGIA ELÉTRICA (ANEEL). Banco de informação de geração: banco de dados. 2005. Disponível em: <http://www.ANEEL.gov.br/15htm>. Acesso em: 15 set. 2021.

BORGES, Fabricio. Q.; BORGES, Fabrini Q.; VATRAZ, S. Gestão da plataforma logística cooperativa: uma contribuição teórica para a realidade energética brasileira. Revista Observatório da Economia Latino-americana. Eumed. Fev, 2018.

BERMANN. C. Energia no Brasil: para quê? Para quem? Crise e alternativas para um país sustentável. São Paulo: Livraria da Física, 2003.

BRASIL. Ministério de Minas e Energia. Balanço de Energia Útil. Brasília, 2005.

BRUM, A. J. Desenvolvimento econômico brasileiro. Rio de Janeiro: Vozes, 1996.

CADASTRO GERAL DE EMPREGADOS E DESEMPREGADOS (CAGED).

Estatísticas das bases de dados do MTE. Disponível em: <https://www.caged.gov.br/index.html>. Acesso em: 21 nov. 2021.

CENTRAIS ELÉTRICAS DO NORTE DO BRASIL (ELETRONORTE). Amazônia: cenários socioeconômicos e de demanda de energia elétrica. Brasília, 2021.

CENTRAIS ELÉTRICAS DO NORTE DO BRASIL. Portal Eletronorte. Disponível em: www.eln.gov.br. Acesso em: 25 jan. 2021.

CENTRAIS ELÉTRICAS DO PARÁ (CELPA). Relatório da administração: exercício de 2005 Belém, 2006.

CENTRAIS ELÉTRICAS DO PARÁ. Relatório da administração: exercício de 2004. Belém, 2005.

CENTRAIS ELÉTRICAS DO PARÁ. Relatório da administração: exercício de 2000. Belém, 2001.

FEARNSIDE, P. M. Emissões de gases do efeito estufa em reservatórios na Amazônia. Manaus: INPA, 1997.

FENZL, N. Estudo de parâmetros capazes de dimensionar a sustentabilidade de um processo de desenvolvimento. In: XIMENES, Tereza (Org.) Perspectivas do desenvolvimento sustentável. Belém: NAEA/UFPA, p. 01-31, 1997.

FENZL, N.; CANTO, A.; VINÍCIUS, M. A evolução do setor energético e o desenvolvimento socioeconômico da região Norte e no Estado do Pará. In: FENZL N.; COELHO, M. C. N.; SIMONIAN, L. (Org.) Estado e políticas públicas na Amazônia: gestão de recursos naturais. Belém: Cesupa; Naea/Ufpa, p. 245-286, 2000.

FILELLINI, A. Economia do setor público. São Paulo: Atlas, 2002.

FISCHER-KOWALSKI M. et al. Gesellschaftlicher stoffwechsel und kolonisierung von natur. Amsterdam: Verlag Fakultas, 1997.

R. gest. sust. ambient., Florianópolis, v. 10, n. 2, p. 245-266, jun. 2021. 
GOLDEMBERG, J.; MOREIRA, J. R. Política energética no Brasil. São Paulo: IEA/USP, 2005.

HIRSCHMAN, A. O. Estratégia do desenvolvimento econômico. Rio de Janeiro: Fundo da Cultura, 1961.

INSTITUTO BRASILEIRO DE GEOGRAFIA E ESTATÍSTICA (IBGE). Pesquisa Nacional a Domicílio. Rio de Janeiro, 2005.

INSTITUTO NACIONAL DE EFICIÊNCIA ENERGÉTICA. (INEE). Boletim do INEE. Rio de Janeiro, 2001.

KEYNES, J. M. The general theory of employment, interest an money.[s/l]: [s/e], 1989.

ORGANIZAÇÃO DAS NAÇÕES UNIDAS. (ONU). Report of the secretary general commission on sustainable development: Work program on indicators of sustainable development. New York: UN/E/CN, 1995.

ORGANIZAÇÃO LATINO-AMERICANA DE ENERGIA. Sistemas de informaciones energéticas e económicas. Quito: SIEE, 1996.

PASSOS, R. C. M.; NOGAMI, O. Princípios de economia. São Paulo: Pioneira, 1987.

REIS, L. B.; FADIGAS, E. A. A.; CARVALHO, C. E. Energia, recursos naturais e a prática do desenvolvimento sustentável. Barueri-SP: Manole (Coleção Ambiental), 2012.

ROSSETTI, J. P. Contabilidade social. São Paulo: Atlas, 2010.

SANTOS, M. A. Inventário das emissões de gases de efeito estufa derivados de hidrelétricas. 2000. 523f. Tese (Doutorado em Planejamento Energético) Coordenação dos Programas de Pós-Graduação de Engenharia, Universidade Federal do Rio de Janeiro, 2000.

SECRETARIA EXECUTIVA DE ESTADO DE PLANEJAMENTO, ORÇAMENTO E FINANÇAS (SEPOF) Relatório da diretoria de estudos, pesquisas e informações socioeconômicas. SEPOF: Belém, 2006.

SPANGENBERG, J. H. Measuring and communicating sustainability with indicators: terms of reference for a CSD core indicator test in main catchment area regions. New York: UN/E/CN.

WORLD COMMISSION ON ENVIRONMENT DEVELOPMENT. Uma visão geral. Oxford: Universidade de Oxford, 2000.

R. gest. sust. ambient., Florianópolis, v. 10, n. 2, p. 245-266, jun. 2021. 